\title{
NOTE
}

\section{Calcium oxalate production in the marine sponge Chondrosia reniformis}

\author{
Carlo Cerrano $^{1, *}$, Giorgio Bavestrello ${ }^{2}$, Attilio Arillo ${ }^{1}$, Umberto Benatti ${ }^{3}$, Stefano Bonpadre ${ }^{4}$, \\ Riccardo Cattaneo-Vietti ${ }^{1}$, Laura Gaggero ${ }^{1}$, Marco Giovine ${ }^{3}$, Luciana Leone ${ }^{4}$, \\ Gabriella Lucchetti ${ }^{1}$, Michele Sarà ${ }^{1}$
}

\begin{abstract}
'Dipartimento per lo Studio del Territorio e delle sue Risorse dell'Università di Genova, Viale Benedetto XV 5, I-16132 Genova, Italy
${ }^{2}$ Istituto di Scienze del Mare dell'Università di Ancona, Via Brecce Bianche, I-60131 Ancona, Italy

${ }^{3}$ Istituto policattedra di Chimica Biologica dell'Università, Viale Benedetto XV 1, I-16132 Genova, Italy

'Dipartimento di Scienze Biomediche dell'Università di Ancona, Via Brecce Bianche, I-60131 Ancona, Italy
\end{abstract}

\begin{abstract}
A constant amount of calcium oxalates, as weddellite and whewellite, has been detected by $X$ ray diffraction analysis in the $\mathrm{NaClO}$ resistant fraction of the tissue of the demosponge Chondrosia reniformis. SEM observations showed that oxalate is present on the surface of living sponges, suggesting that the crystals are produced inside and/or on the sponge surface. The output of oxalate crystals through the sponge ectosome represents a significant percentage of sediments collected by sediment traps placed in a C. reniformis population. HPLC analyses allowed the detection of high levels of ascorbic acid in the sponge's tissue; the spontaneous conversion of the ascorbic acid to oxalic acid, well known in plants, may explain the oxalate occurrence. Although the ascorbic acid is involved in the biosynthesis of collagen, the release of ascorbic/oxalic acid through the sponge surface may be utilised to ward off other benthic organisms during competition for space and as an antifeeding mechanism against possible predators.
\end{abstract}

KEY WORDS: Oxalate . Ascorbic acid Porifera. Biomineralization

Chondrosia reniformis is an Atlanto-Mediterranean demosponge characterised by the absence of a spicular skeleton. Its ectosome, the outer portion of the sponge, is composed by a thick ( 2 to $5 \mathrm{~mm}$ ) collagenous layer reinforced by a large amount of allochthonous material (up to 3000 sand grains $\mathrm{cm}^{-2}$ of ectosome in high sedimenting conditions). Field observations and laboratory experiments indicate that this species selects and incorporates siliceous materials, in particular quartz particles and opaline sponge spicules (Bavestrello et al. 1996). Whereas the opaline sponge spicules remain

·E-mail: zoologia@unige.it unaltered within the sponge tissue the engulfed quartz particles are quickly etched, homogenised to a size of about $30 \mu \mathrm{m}$ and discharged out of the sponge. This activity was hypothesised to be performed by an organic acid, and ascorbic acid seemed to be the most likely (Bavestrello et al. 1995).

Previous data (Bavestrello et al. 1996) indicate that, in the $\mathrm{NaClO}$ resistant fraction of the sponge tissue, a consistent amount of calcium oxalate was generally present. Deposits of this mineral are very rare in marine invertebrates (Lowenstain 1968, Saffo \& Lowenstain 1978). In this study we report on the phenomenon of oxalate production from both a morphological and an ecophysiological point of view.

Materials and methods. In order to quantitatively study the minerals incorporated by Chondrosia reniformis we dissolved 10 specimens collected in the Ligurian Sea in $\mathrm{NaClO} 15 \%$ and examined the remaining fractions using a Siemens $X$ ray diffractometer with $\mathrm{Ni}$ filtered CuKa radiation.

To analyse the mineralogical characteristics of the sediment close to the studied specimens, 3 sediment traps were placed inside the $C$. reniformis populations on a vertical cliff, at each of 10, 15 and $25 \mathrm{~m}$ depths (Portofino Promontory, Ligurian Sea, Italy). Sediments were collected monthly from November to April 1997. Successively the fine fraction ( $\mathrm{f}>0$ ) was studied by $\mathrm{X}$ ray diffraction analyses

The ultrastructural characteristics of the crystals present on the sponge ectosome were observed by SEM (scanning electron microscope) micrographs on 10 specimens. Ectosome samples were fixed directly underwater in $2.5 \%$ glutaraldehyde, left in this 


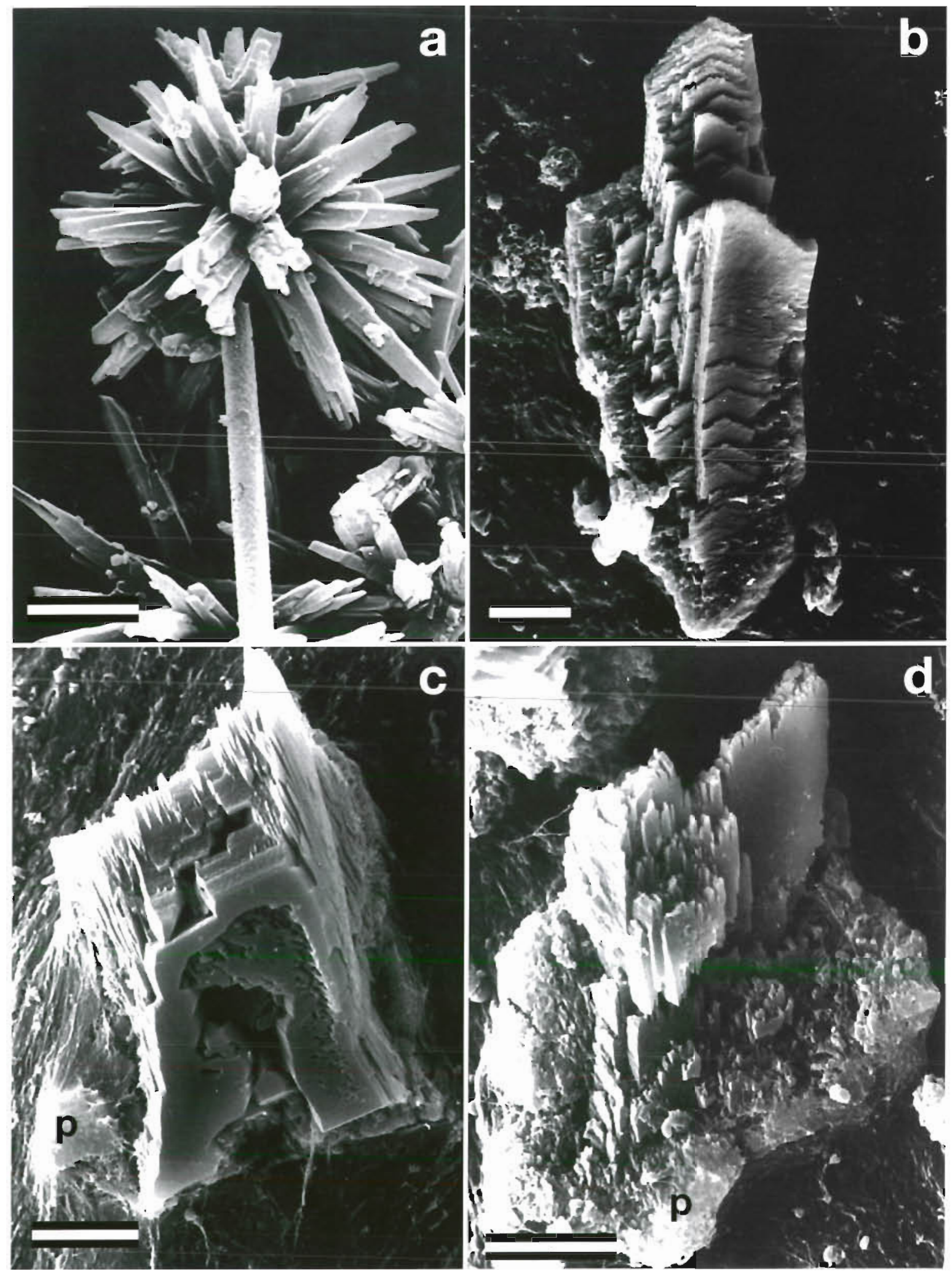

Fig. 1. Crystals of calcium oxalate produced by Chondrosia reniformis. (a) Dendritic growth of weddellite from the NaClO resistant fraction. The presence of both elongated and blunt crystals suggests that the concentration of the feeding solution was variable. (b to d) Crystals showing tetragonal symmetry. More developed faces are $\{100\}$ and subordinate $\{001\}$. In (b) and (c) crystals are elongated on the $[001]$ edge. Crystals shown in (c) and (d) are protruding from the sponge ectosome $(\mathrm{p}=$ pinacocyte). (Scale bars $=10 \mu \mathrm{m})$ 
medium for $1 \mathrm{~h}$, then rinsed in artificial sea water and dehydrated in graded ethanols. Samples were criticalpoint-dried using liquid $\mathrm{CO}_{2}$ in a Bomar apparatus.

Owing to the hypothesis that ascorbic acid is the main factor responsible for the quartz dissolution recorded in this species, this organic acid was detected in the sponge tissue. Analyses were conducted on 10 specimens, with a HPLC system consisting of a Varian (Walnut Creek, CA, USA) Model Vista 5500, following procedures described by Lloyd et al. (1987) and Rose \& Bode (1995).

Results and discussion. Diffractometer analyses indicated that the main mineral fractions present inside the sponge body are: opaline sponge spicules (40 to $70 \%$ ); quartz (20 to $40 \%$ ); and a constant amount of calcium oxalate, as weddellite (di-hydrate Ca-oxalate: 5 to $6 \%$ ) and whewellite (mono-hydrate Ca-oxalate: 2 to $3 \%$ ). The occurrence and the proportions of crystals of calcium oxalate in the $\mathrm{NaClO}$-resistant fraction were confirmed by microscopical observation with polarised light. SEM observations show the skeletal habit that produces lamellar, radiating or dendritic textures (Fig. 1a,b), suggesting high growth rates along corners and edges, and fast nucleation rates from oversaturated solutions. SEM analysis of intact sponge surfaces showed several crystals of the same type (up to $250 \mathrm{~mm}^{-2}$ ) emerging from the sponge ectosome, sometimes partially covered by pinacocytes (Fig. 1c,d). The close relationship with the sponge cells, the lack of mechanical abrasion and the mineral habit indicate that grains were produced inside and/or on the sponge surface. Microprobe analyses, performed in the energy dispersive mode, revealed calcium as the major component. The habit, very similar to that observed in the $\mathrm{NaClO}$-resistant fraction of the sponge, allowed us to conclude that these crystals are composed of calcium oxalate.

The output of oxalate crystals through the sponge ectosome induced us to evaluate the contribution of this mineral to local sedimentation by using sediment traps. The $X$ ray diffaction analysis of the sediment collected monthly during 1997 indicated that calcium oxalate crystals (both weddellite and whewellite) are on average $2.3 \pm 0.8,9.2 \pm 2.5$ and $11 \pm 1.8 \%$ of the total sediments, respectively, at the 3 depths. Trapped grains show the same habit as those observed within the sponge, and are devoid of evidence of mechanical abrasion, thus confirming their derivation from sponges. To date, the presence of oxalates in sediments has been recorded exclusively from the Weddell Sea, in nodules together with Ca-citrate (earlandite), and interpreted as authogenic minerals of deep water sediments (Lowenstain 1968).

The relatively large amount of calcium oxalate produced by Chondrosia reniformis raises the issue of the metabolic pathways involved in its biosynthesis and its ecological role. In plants, ascorbic acid is generally as- sumed to be one of the major precursors of oxalic acid (Franceschi \& Horner 1980). In mammals there is also evidence that high ascorbic acid intake increases urinary oxalate levels and may lead to the formation of calcium oxalate stones in kidneys and other regions of the urinary system (Roth \& Breitenfield 1977). Previously (Bavestrello et al. 1995) we have identified ascorbic acid as the chemical agent involved in quartz dissolution in the sponge $C$. reniformis. Our HPLC analysis of ascorbic acid concentrations in $C$. reniformis from Portofino cliff revealed levels of this organic acid ranging from 1 to $10(x=2.89 \pm 0.8) \mu g^{-1}$ wet weight of sponge tissue. These levels are of the same order of magnitude as that observed in plants (Loewus 1980).

The presence of oxalate crystals on the surface of Chondrosia reniformis may be due to rapid precipitation of ascorbic acid diffused through the ectosome cells. In fact, it is known that ascorbic acid may spontaneously convert to oxalic acid in slightly alkaline conditions such as those of sea water. In plants, the ascorbic acid is considered a scavenger of free radicals deriving from photosynthetic activity (Roth \& Breitenfield 1977) and acts as a protective device against foraging animals (Kingsbury 1964, Sanz \& Reig 1992). In animals, the presence of calcium oxalate is usually considered to be pathological (e.g. urinary stones of mammals). Anyway weddellite crystals have been observed in an Antarctic gastropod (Lowenstain 1968) and a Californian tunicate (Saffo \& Lowenstain 1978): in both cases, these oxalate concretions have been considered to be non-pathologic with unknown function.

In the sponge Chondrosia reniformis ascorbic acid is involved, as reducing agent, in the intensive biosynthesis of collagen, the major component of this sponge (Garrone 1978). In addition, the release of ascorbic/ oxalic acid through the sponge surface may be utilised to ward off other benthic organisms during competition for space and as an antifeeding mechanism against possible predators. The data presented here extend the range of oxalate precipitation reported in marine invertebrates and represent the first record of this mineral in lower metazoans. Moreover it provides evidence, from a sedimentological point of view, of the local role of the sponge $C$. reniformis in the enrichment of the sediments by this uncommon mineral.

\section{LITERATURE CITED}

Bavestrello G, Arillo A, Benatti U, Cerrano C, Cattaneo-Vietti R, Cortesogno L, Gaggero L, Giovine M, Tonetti M, Sarà M (1995) Quartz dissolution by the sponge Chondrosia reniformis (Porifera, Demospongiae). Nature 378:374-376 Bavestrello G, Cerrano C, Cattaneo-Vietti R, Calabria F, Cortesogno L, Sarà M (1996) Selective incorporation of foreign material in Chondrosia reniformis. Ital J Zool 63: $215-220$ 
Franceschi VR, Horner TH (1980) Calcium oxalate crystals in plants. Bot Rev 46:361-427

Garrone R (1978) Phylogenesis of connective tissue. Karger, Basel

Kingsbury JM (1964) Poisonous plants of the United States and Canada. Prentice-Hall, Inc, Englewood Cliffs, NJ

Lloyd LL, Warner FP, White CA, Kennedy JF (1987) Quantitative reversed phase HPLC analysis of L-ascorbic acid (Vitamin C) and identification of its degradation products. Chromatographia 24:371-376

Loewus FA (1980) L-ascorbic acid: metabolism, biosynthesis function. In: Preiss J (ed) The biochemistry of plants, Vol 3. Academic Press, p $77-99$

Editorial responsibility: Otto Kinne (Editor),

Oldendorf/Luhe, Germany
Lowenstain HA (1968) Weddellite in a marine gastropod and in Antarctic sediments. Science 162:1129-1130

Rose RC, Bode AM (1995) Analysis of water-soluble antioxidants by high-pressure liquid chromatography. Biochem $J$ 306: 101-105

Roth DA, Breitenfield RV (1977) Vitamin C and oxalate stones. J Am Med Assoc 237:768

Saffo MB, Lowenstain HA (1978) Calcareous deposits in the renal sac of a molgulid tunicate. Science 200: $1166-1168$

Sanz P, Reig R (1992) Clinical and pathological findings in fatal plant oxalosis. A review. Am. J Forensic Med Pathol $13: 342-345$

Submitted: October 30, 1998; Accepted: February 8, 1999 Proofs received from author(s): March 26, 1999 